
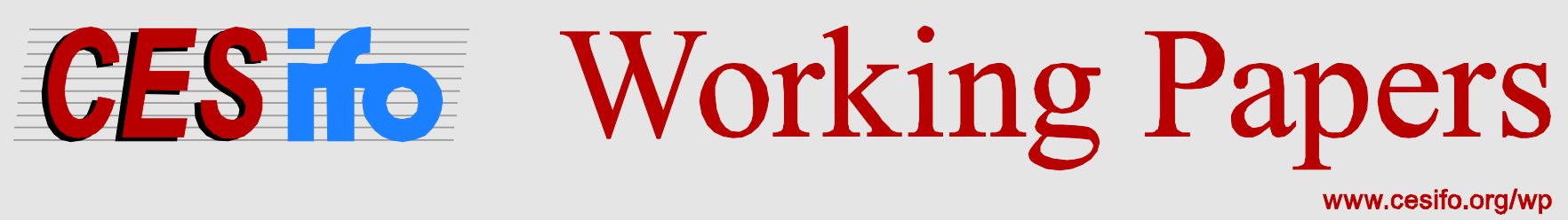

\title{
Social Security Transfers and the Marginal Cost of Public Funds
}

\author{
Geir H. M. Bjertnæs
}

\section{CESIFO WORKING PAPER NO. 5689 \\ CATEgORY 1: PUBlic FinANCE \\ DECEMBER 2015}
An electronic version of the paper may be downloaded
- from the SSRN website: Www.SSRN.com
- from the RePEc website: Www.RePEc.org
- from the CESifo website: www.CESifo-group.org/wp




\title{
Social Security Transfers and the Marginal Cost of Public Funds
}

\begin{abstract}
Recent estimates of the marginal cost of public funds differ substantially. Some studies argue that the efficiency cost of taxation counter the welfare gain connected to redistribution of income. Hence, the efficiency cost of taxation should not be included as a cost of public goods provision. Kleven and Kreiner (2006), however, argue that the cost of public goods provision may double in countries with a large welfare state due to exit from the labor market. This study shows that the cost of public goods provision should be increased with less than 15 percent when categorical transfers redistributed income even though taxation may lead to exit from the labor market.
\end{abstract}

JEL-Codes: H210, H230, H410.

Keywords: marginal cost of public funds, optimal income taxation, categorical transfers, tagging.

\author{
Geir H. M. Bjertnces \\ Statistics Norway \\ Research Department \\ P.O. Box 8131 Dep \\ Norway-0033 Oslo \\ ghb@ssb.no
}

I am highly grateful for valuable comments by Bas Jacobs, Vidar Christiansen, Floris Zoutman, participants at the IIPF conference 2015, participants at the 9th Norwegian German Seminar on Public Economics, participants at the Nordic Workshop in Public Economics 2015, participants at the OFS internal workshop 2015, as well as participants of seminars at the Ministry of Finance in Norway and Statistics Norway. 


\section{Introduction}

Public projects are usually financed with tax revenue from distorting taxes. The cost of such distortions are incorporated into cost-benefit analyses by multiplying costs with a factor, MCF, or the marginal cost of public funds. The Traditional approach by Stiglitz and Dasgupta (1971), Atkinson and Stern (1974), and Browning (1976) consisted of calculating the efficiency cost of raising additional tax revenue when taxation distorted the intensive margin labor/ leisure choice. Recent literature, however, that takes account of concerns for the distribution of income estimate MCF around one, see Kaplow (1996), Sandmo (1998), Christiansen (1981), Christiansen (2007) and Jacobs (2013). Estimates differ with assumptions, but the main argument is that the efficiency cost of taxation counter the welfare gain connected to redistribution of income. Hence, there should be no additional cost attached to raise public funds when public goods are provided.

These studies design tax and transfer systems based on observed income of individuals, as the government is assumed not to observe the ability of each individual. Hence, transfers to redistribute income are given uniformly to all individuals. Most countries have, however, adopted categorical social transfer schemes, where individuals are classified into groups. Individuals are classified as disabled or sick by doctors, old aged are classified as retired, (single) parents with children receive child benefit, and social security transfers are only offered to individuals that satisfies a set of requirements. Akerlof (1978) show that such tagging improves welfare as less distorting taxes is needed when transfers are limited to tagged groups. Hence, improved tools to redistribute income are likely to increase the welfare gain of public transfers. An unresolved question is whether the welfare gain of public goods provision should match the higher welfare gain of categorical transfers to disabled groups.

The empirical literature show that variation in the supply of labor is mostly generated by changes in labor force participation by people at the lower end of the earnings distribution, see Heckman (1993), Blundell, MaCurdy (1999), Eissa and Liebman (1996) and Meyer and Rosenbaum (2001). The participation tax rate which distorts labor force participation, consisting of both income taxation and loss of transfers, is also substantial in many countries according to Immervoll et al (2007). Hence, income taxation to finance public goods provision is likely to create substantial distortions due to exit from the labor market. Kleven and Kreiner (2006) show that incorporation of such extensive margin labor/ leisure choices leads to a substantial increase in estimates of MCF. Estimates increase from the interval 0,850,93 to the interval 1,26-2,20 within their basic scenario. Kleven and Kreiner (2006), however, do not consider income taxation in combination with adjustments in transfers to non-workers, or adjustments in tax credits to low income earners, to alleviate extensive margin distortions. The extensive margin distortion could have been neutralized if the income tax increase had been combined with a reduction in social benefit transfers so that the 
participation tax rate was kept constant. Indeed, Saez (2002) and Immervoll et al. (2007) show that optimal income tax/ transfer programs in the presence of extensive margin distortions should stimulate entry by offering tax credits similar to the Earned Income Tax Credit in the US.

Tagging of transfers is also likely to reduce extensive margin distortions for two additional reasons. First, disability benefit programs contain incentives that exclude disabled from working according to OECD (2009). Kost $\varnothing 1$ and Mongstad (2014), however, find that recipients have considerable capacity to work that can be effectively induced by providing financial work incentives. Indeed, a substantial share of intended recipients of welfare programs do not get social benefit transfers, see Moffitt (2003), Currie (2006). In EU countries, about 30 percent of people who report severe disability do not get disability benefits, and choose to work according to Eurostat (2001). Hence, extensive margin distortions can be reduced by offering transfers to disabled that decide to work. Second, tagging imply that transfers are restricted to disabled only. Extensive margin distortions are consequently reduced as the participation tax rate for individuals that do not qualify for transfers is reduced.

The aim of this study is to explore how MCF should be adjusted in the presence of extensive margin distortions when categorical transfers redistribute income so that the welfare is maximized. Hence, the insight from the literature on MCF and redistribution is extended with categorical transfers and extensive margin distortions. A well-established result is that categorical transfers should be set so as to eliminate inequality in the average social marginal value of income between tagged groups, see e.g. Viard (2001). Simple arguments uncover that the MCF equals one in the presence of quasilinear utility functions and group specific transfers which eliminate inequality in the average social marginal value of income between groups. The average social marginal value of income is however larger for the disabled group when the size of this group is sufficiently large and lump-sum transfers are constrained to be non-negative ${ }^{2}$, see Slack (2015). The present study investigates implications for MCF in this case, and shows that MCF exceeds one in the presence of categorical transfer systems. The MCF exceeds one even though the income tax is chosen so that the efficiency cost of taxation is balanced against the distributional welfare gain. The intuition is that categorical transfers improve the welfare impact of social transfer schemes. The welfare gain of public goods provision has to match the welfare gain of categorical transfer in a welfare maximizing solution.

\footnotetext{
${ }^{2}$ This constraint on transfers could be implemented to prevent social turmoil and potential riots connected to positive lump-sum taxation. Indeed, the Thatcher government imposed lump-sum taxes in 1990 in England. It created social turmoil and riots in several cities before it was abandoned later that year.
} 
The impacts of incorporating extensive margin distortions are marginal and negative compared with a solution where the extensive margin distortion is excluded. The MCF for the US economy is reduced from 1,102 to 1,087 and from 1,048 to 1,042 when the intensive margin labor supply elasticity equals 0,2 and 0,1 , respectively. The intuition is that transfers to non- working disabled generate extensive margin distortions. Hence, it is optimal to redistribute less to non- working disabled. The marginal utility of income for this group increases. A higher average marginal utility of income contributes to lower MCF as the value of public funds measured in units of private income is reduced. The difference in results compared to Kleven and Kreiner (2006) emerges because less transfers to non- workers due to extensive margin distortions contributes to lower MCF as the average marginal utility of income increases. Estimates in Kleven and Kreiner (2006) are entirely focused on the efficiency aspect of taxation even though the impact of incorporating redistribution is discussed.

The welfare cost of correcting for the extensive margin distortions is larger in a scenario where the government is unable to differentiate between transfers to productive and disabled that are working. Estimates of MCF are slightly below one in this case. The intuition is that transfers to non- working disabled are lowered to take account of the additional cost of correcting for extensive margin distortions. Hence, the marginal utility of income for this group increases. This contributes to lower MCF as the value of public funds measured in units of private income is reduced.

Section 2 presents the model and calculates formulas. Section 3 present estimates of MCF, while section 4 concludes.

\section{The model framework}

The design of the model framework and available tax and transfer system is crucial for calculations of MCF as the marginal welfare cost of collecting additional tax revenue equals the marginal welfare gain of redistributing transfers in a welfare maximizing solution. The welfare gain of a one dollar transfer to all individuals in the case with quasilinear utility functions equals the sum of the marginal utility of income for all individuals. The marginal welfare gain of redistributing one dollar is found by dividing this sum by the number of individuals. Hence, this welfare gain equals the average marginal utility of income.

The MCF measures the amount of private income the welfare maximizing government is willing to sacrifice for one additional unit of income in the public sector. Hence, the MCF is 
defined as the shadow price of public funds divided by the average marginal utility of income in most recent studies. The shadow price of public funds equals the average marginal utility of income in the case with quasilinear utility functions and uniform transfers to all individual. This explains why the MCF equals one in this case. Sandmo (1998) show that MCF is smaller than one when leisure is a normal good and taxation distorts the supply of labor. A reduction in transfers to finance public goods provision boosts the supply of labor, and hence, alleviates the distortion. The present study assumes quasiliner preferences for working individuals, and hence, excludes the income effect on the supply of labor.

Tagging implies that the government can design a separate income tax function for each tagged group of individuals, including uniform within group transfers. A welfare maximizing government can redistribute transfers to each group, so that the average marginal utility of income is equalized between groups, see Viard (2001). The shadow value of public transfers therefor equals the average marginal utility of income when utility functions are quasilinear. This explains why the MCF equals one in this case as well.

However, a sufficiently large fraction on social welfare benefits in combination with a nonnegative constraint on transfers implies that taxation required to equate average social marginal value of income between groups is too harmful. Hence it is suboptimal to equate the social marginal value of income between tagged groups in this case according to Slack (2015). Transfers to the productive group of individuals equals zero in this case as positive lump-sum taxes are excluded by assumption. Indeed, pure positive lump-sum taxes to productive workers are not observed even though tax and transfer systems differ.

Governments instead opt for distorting taxation to finance redistribution to needy groups. This study explores the implications for MCF within this context. A special case is also analyzed where the government is unable to differentiate policy between healthy and disabled individuals that are working.

The model framework is designed to calculate MCF when a welfare maximizing government allocates public funds to public goods provision. A linear income tax distorts the intensive margin labor/ leisure choice of working individuals with quasilinear utility functions. The government is assumed to be able to perfectly separate between two groups of individuals. Transfers to non-working within the disabled group distort the extensive margin labor/ leisure choice due to exit from the labor market. Transfers to working individuals within the disabled group contribute to neutralize this distortion. The government is assumed to maximize the welfare by balancing the efficiency cost of distorting income taxation against the welfare gain of such transfers. Lump-sum taxes on productive working individuals are excluded. This assumption is implemented to investigate cases with a sufficiently large welfare state, see Slack (2015). 


\subsection{The behavior of individuals}

There are two types of individuals in the economy with preferences for leisure, $l_{i}$, private consumption, $c_{i}$, and consumption of public goods, $z$. Utility functions are identical for all individuals except for one feature. Type 2 individuals experience a loss of utility connected to entering the labor market. This loss differ between type 2 individuals. This utility function is quasilinear for consumption above a given level, $\hat{c}$.

Individuals of type 1 and 2 differ with respect to productivity, which is given by their respective wage rates, $w_{i}$. All $\hat{N}$ type 1 individuals are working. The higher type 1 wage rate imply a consumption level which exceeds $\hat{c}$. Hence, the utility function of type 1 individuals, $U_{1}$, are given by

(1) $U_{1}=c_{1}+g\left(l_{1}\right)+f(z)$

Inada conditions are assumed for $f(z)$. Consumption is given by after tax wage income, where $w_{1}$ equals the wage rate of type 1 individuals, $h_{1}$ equals hours of work, and $t$ equals the tax rate

(2) $c_{1}=(1-t) w_{1} h_{1}$

The time constraint of type 1 individuals is given by

(3) $h_{1}=T-l_{1}$

Individuals of type 1 maximize their utility, given by equation (1), conditional on their budget equation (2), and their time constraint, equation (3). First order conditions of this optimization problem gives

(4) $\lambda=1$

The marginal utility of income, $\lambda$, equals one for all levels of consumption above $\hat{c}$.

(5) $\frac{\partial g}{\partial l_{1}}=(1-t) w_{1}$

The marginal rate of substitution between leisure and private consumption equals the after tax wage rate. The partly quasi linear utility function implies that the leisure is given by the tax rate, $t$.

(6) $l_{1}=l_{1}(t) \quad \frac{\partial l_{1}}{\partial t} \geq 0$

Hence, the indirect utility of type 1 individuals equals 
(7) $u_{1}=(1-t) w_{1}\left(T-l_{1}(t)\right)+g\left(l_{1}(t)\right)+f(z)$

Note that the choice of leisure is not influenced by the income effects of taxation. This assumption excludes tax base effects due to income effects, but simplifies calculations of MCF.

Type 2 individuals with a sufficiently low loss of utility connected to entering the labor market is assumed to choose a fixed number of working hours. Note that empirical observations uncover that almost no worker chooses low annual or weekly hours of work, see Eissa et al. (2004). Discrete entry is typically explained by fixed costs (both emotional and fixed working costs) connected to enter the labor market which differ between individuals, see Cogan (1981). Consumption of working type 2 individuals exceeds $\hat{c}$, Hence, preferences of type 2 individuals are represented by the utility function, $U_{2}$ :

(8) $U_{2}=c_{2}+g\left(l_{2}\right)-e_{i}+f(z)$,

Their accumulated cost of entering the labor market equals

(9) $\frac{1}{2} \alpha N^{2}$

Hence, the working disabled with the highest entry cost equals $e_{i}=\alpha N$, where $\alpha$ is a parameter which determine the size of the entry cost. Working type 2 individuals receive a net transfer, $a$, from the government. Income tax payments are subtracted from this transfer. Consumption is given by

$$
\text { (10) } c_{2}=w_{2} h_{2}+a
$$

Their indirect utility is given by

(11) $u_{2}=w_{2} h_{2}+a+g\left(\bar{l}_{2}\right)-e_{i}+f(z)$

The labor supply for type 2 individuals, $h_{2}^{n}$, with a sufficiently high disutility for working equals zero.

(12) $h_{2}^{n}=0$

Hence, consumption of non-working type 2 individuals equals transfers, $b^{3}$.

(13) $c_{2}^{n}=b$

\footnotetext{
${ }^{3}$ Income tax payments are subtracted from this transfer.
} 
These transfers can be lower than $\hat{c}$. Hence, the indirect utility of non-working type 2 individuals is given by

$$
\text { (14) } u_{2}^{n}=S(b)+g(T)+f(z), \text { where } S^{\prime}(0)=\infty, \mathrm{S}^{\prime}>1 \text { and } \mathrm{S}^{\prime \prime}<0 \text { when } c_{2}<\hat{c} \text {. }
$$

The number of type 2 individuals equals $\bar{N}$, and the number of working type 2 individuals equals $N$. The equilibrium condition which determines the number of type 2 individuals which is working is given by

(15) $w_{2} h_{2}+a+g\left(\bar{l}_{2}\right)-\alpha N=S(b)+g(T)$

This equation determines $N$ as a function of $b$ and $a$. Hence, the size of the social benefit transfers is affecting the number of disabled that decide to work. These assumptions are implemented to highlight the extensive margin choice, and to simplify calculations. The intensive margin distortion is however excluded.

(16) $N=N(b, a)$

The potential welfare gain of redistributing one unit of the consumer good from working to non-working individuals equals the difference in their marginal utility of income, $\frac{\partial S}{\partial b}-1$. This specification is consistent with literature on reported happiness, which finds a strong positive correlation between reported happiness and income for low income levels, and a positive connection for higher income levels, see Deaton (2008) and Stevenson and Wolfers (2008). The specification of utility functions implies that there is no potential welfare gains connected to redistributing income between working individuals. The policy tool to harvest such welfare gains, transfers to the group of productive workers, is excluded. Hence, this specification of utility functions is not likely to influence results.

The present study assumes that the marginal utility derived from public good provision is equalized between individuals. The study also assume that the productivity and tax revenue generated is unaffected by the provision of public goods. These assumptions are crucial for results, see Sandmo (1998). Kaplow (1996).

\subsection{The government's optimization problem}

The government maximizes an individualistic social welfare function given the budget constraint of the government. 
(17)

$$
\begin{gathered}
\underset{z, t, b, a}{\operatorname{Maks}} \hat{N}\left[(1-t) w_{1}\left(T-l_{1}(t)\right)+g\left(l_{1}(t)\right)+f(z)\right]+N(b, a)\left[w_{2} h_{2}+a+g\left(\bar{l}_{2}\right)\right]-\frac{1}{2} \alpha(N(b, a))^{2}+ \\
(\bar{N}-N(b, a))(S(b)+g(T))+\bar{N} f(z)
\end{gathered}
$$

Given the budget constraint

(18) $\hat{N} t w_{1}\left(T-l_{1}(t)\right)=q z+(\bar{N}-N(b, a)) b+N(b, a) a$

The Lagrangian is given by

$$
\begin{aligned}
& L=\hat{N}\left[(1-t) w_{1}\left(T-l_{1}(t)\right)+g\left(l_{1}(t)\right)+f(z)\right]+N(b, a)\left[w_{2} h_{2}+a+g\left(\bar{l}_{2}\right)\right]-\frac{1}{2} \alpha(N(b, a))^{2}+ \\
& (\bar{N}-N(b, a))(S(b)+g(T))+\bar{N} f(z)+\mu\left[\hat{N} t w_{1}\left(T-l_{1}(t)\right)-q z-(\bar{N}-N(b, a)) b-N(b, a) a\right]
\end{aligned}
$$

The price of public goods is denoted q, and the shadow value of public funds is denoted $\mu$. Fairly reasonable restrictions on $g\left(l_{1}\right), l_{1}(t), f(z)$ and $S(b)$ imply that the lagrangian is concave, see appendix A. The first order conditions and calculations necessary to estimate $\mathrm{MCF}$ is presented in appendix B. Key equations to determine variables necessary to estimate MCF are presented below.

The provision of public goods can be determined by instructing government agencies to implement all projects that pass the cost- benefit test, where costs are multiplies by the MCF. The MCF is defined as the shadow value of public funds divided by the average marginal utility of income, $\bar{\lambda}$, in most recent studies. The $\bar{\lambda}$ - parameter is necessary in the definition to convert the welfare effect of public funds into units of income/ consumption goods. The present study calculates the MCF based on this definition.

Previous studies have adopted different definitions of the MCF, see Jacobs (2009). The PigouHarberger-Browing approach differs from the Atkinson-Stern-Ballard-Fullerton approach, and it remains unclear which measure to use for social cost benefit analysis. Jacobs (2013) adopts a third approach where MCF is defined as the shadow value of public funds divided by the average of the social marginal value of private income instead of the average marginal value of private income. The denominator in his definition includes the welfare effects of income effects on taxed bases. He shows that MCF equals one with an optimal linear and nonlinear income tax with this approach. Indeed, the MCF equals one within a fully flexible tax system according to Christiansen (2007). 
The aim of all studies is however to arrive at an MCF that implements the socially desirable supply of public goods. The present study contributes by calculating the welfare maximizing deviation from the Samuelson rule. The MCF that should be used in cost benefit analysis is found by multiplying costs, i.e. the marginal rate of transformation between private and public goods, with a factor required to implement the welfare maximizing supply of public goods. Multiplying costs within cost- benefit tests with this factor (MCF), and realizing projects which pass this test will implement the welfare maximizing supply of public goods.

The MCF defined as the shadow value of public funds divided by the average marginal utility of income is presented in equation (20).

(20) $M C F=\frac{\mu}{\bar{\lambda}}$

Equation (20) state that MCF equals the marginal value of public funds measured in welfare units, $\mu$, divided by the average marginal utility of income, $\bar{\lambda}$. Hence, the MCF can be interpreted as the MRS between private and public income, i.e. the number of goods consumed by privates the government is willing to forgo to increase government consumption with one.

The shadow value of public funds, $\mu$, which is the numerator on the right hand side of equation (20) is determined by the intensive margin labor supply elasticity and the income tax rate.

$$
\text { (21) } \mu=\frac{1}{\left[1-\frac{\partial h_{1}}{\partial w} \frac{w}{h_{1}} \frac{t}{(1-t)}\right]} \text {. }
$$

The shadow value of public funds, $\mu$, equals one when the intensive margin labor supply elasticity equals zero ${ }^{4}$. The shadow value of public funds equals 1,11 and 1,25 when the tax rate equals 0,5 and the intensive margin labor supply elasticity equals 0,1 and 0,2 , respectively.

The average marginal utility of income, which is the denominator on the right hand side of equation (20), becomes

\footnotetext{
${ }^{4}$ Incorporating income effects into the utility function do not alter this outcome.
} 
(22) $\bar{\lambda}=\frac{\hat{N}+N+(\bar{N}-N) \frac{\partial S}{\partial b}}{\hat{N}+\bar{N}}$

The average marginal utility of income is determined by labor force data and the marginal utility of income for non-working disabled, $\frac{\partial S}{\partial b}$, given by equation (23).

$$
\text { (23) } \frac{\partial S}{\partial b}=\frac{\left[1-\frac{\frac{\partial N}{\partial b}(b-a)}{\bar{N}-N(b, a)}\right]}{\left[1-\frac{\frac{\partial l_{1}}{\partial t} t w_{1}}{w_{1}\left(T-l_{1}(t)\right)}\right]}>1 \text { if } \frac{\partial l_{1}}{\partial t}>0, \frac{\partial N}{\partial b}<0 \text { and } b>a \text {. }
$$

Equation (23) shows that there are two reasons why transfers to non-working disabled are restricted so that their marginal utility of income exceeds one. First, collecting tax revenue to finance such transfers distorts the intensive margin labor/ leisure choice of working individuals. This effect is given by the denominator on the right hand side of equation (23). Second, transfers distort the extensive margin labor/ leisure choice of disabled, given by the numerator on the right hand side of equation (23).

The optimal choice of transfers to working disabled, $a$, is chosen so that there is a link between the extensive margin distortions and the shadow price of public funds, $\mu$.

(24) $\mu \frac{\partial N}{\partial a}(b-a)=\mu N-N$

The right hand side of (24) equals the cost of a marginal increase in public funds spent on transfers to working disabled, $\mu N$, minus the direct increase in utility of working disabled, $N$. This equals the left hand side, which is the welfare gain connected to the drop in transfers to disabled as several disabled decide to enter the labor force, $\mu \frac{\partial N}{\partial a}(b-a)$. Hence, the marginal utility of income for non-working disabled, $\frac{\partial S}{\partial b}$, can be determined by labor force data and the shadow value of public funds, $\mu$.

$$
\text { (25) } \frac{\partial S}{\partial b}=\frac{\mu(\bar{N}-N)}{\bar{N}-N+(1-\mu) N}
$$

Equation (22) into equation (20) gives 
(26) $M C F=\frac{\mu}{\frac{\hat{N}+N+(\bar{N}-N) \frac{\partial S}{\partial b}}{\hat{N}+\bar{N}}}$

Equation (25) and (21) together with equation (26) determines MCF as a function of labor force data, the intensive margin labor supply elasticity, and the income tax rate.

The alternative approach consists of calculating the optimal deviation from the Samuelson rule. The first step consists of investigating whether the approach where MCF is defined as $\mu / \bar{\lambda}$ constitutes an optimal deviation from the Samuelson rule. First order equations and the definition of MCF in equation (20) gives

$$
\text { (27) } \frac{(\hat{N}+\bar{N}) \frac{\partial f}{\partial z}}{\bar{\lambda}}=M C F q
$$

The left hand side of equation (27) equals the number of private consumer goods a welfare maximizing government is willing to sacrifice for one additional unit of the public good, i.e. the MRS between private and public goods from the perspective of the government, see appendix C. The right hand side of equation (27) equals the marginal cost of public funds defined as $\mu / \bar{\lambda}$, multiplied by the price of public goods measured in units of the private good. Hence, this approach differs slightly compared to the approach where MCF is defined as the optimal deviation from the Samuelson rule. A difference emerges because the original Samuelson rule defines the marginal rate of substitution between private and public goods differently.

The optimal deviation from the Samuelson rule is found by adding consumers' marginal rate of substitution between private and public goods, and setting this equal to the marginal rate of transformation multiplied with the welfare maximizing marginal cost of public funds, $M C F_{\text {Samuelson }}$. Calculations, which are presented in appendix D, imply that

$$
\text { (28) }(\hat{N}+\bar{N}) \frac{\partial f}{\partial z}+(\bar{N}-N) \frac{\frac{\partial f}{\partial z}}{\frac{\partial S}{\partial b}}=M C F_{\text {Samuelson }} q
$$

The left hand side of equation (28) equals the accumulated marginal rate of substitution between private and public goods. The right hand side equals the marginal rate of 
transformation, $q$, multiplied with the welfare maximizing marginal cost of public funds, $M C F_{\text {Samuelson }}$.

\section{Results}

This section calculates MCF for a large welfare state country, Norway, and a small welfare state country, the US. Most countries will have a relative size of the welfare state between these two countries. Different estimates of MCF are obtained by implementing necessary labor market data into the model framework. Special cases where taxation do not distort the intensive or the extensive margin labor choice is presented in section 3.1 and 3.2, respectively. Section 3.3 present estimates when taxation distorts both extensive and intensive margins. Both distortions are also present in section 3.4, but differentiation of transfers between disabled and productive individuals that are working is assumed not to be possible. Estimates within each scenario are calibrated to labor force data to obtain empirically relevant estimates. The difference between scenarios should not be interpreted as changes generated by policy, as such changes in policy may alter labor force outcomes.

\subsection{No intensive margin distortions}

This section estimates MCF when it is assumed that taxation do not distort the intensive margin choice of labor supply, i.e. $\frac{\partial h_{1}}{\partial w}=0$. Kinked indifference curves are required to obtain this solution. This assumption is sufficient to determine the MCF. Hence, the estimate holds for any combination of labor force data.

Consider the case where taxation is non-distortionary, i.e. $\frac{\partial h_{1}}{\partial w}=0$. Equation (21) implies that $\mu=1$. Equation (24) becomes

$$
\text { (29) } \frac{\partial N}{\partial a}(b-a)=0
$$

Hence, the welfare maximizing choice of $a$ is to set $a=b$. Implementing these solutions into equation (25) gives $\frac{\partial S}{\partial b}=1$, which imply that transfers to non- working disabled individuals is carried out to the point where the marginal utility of income equals unity. The intuition is that 
the potential welfare gain of redistributing income is completely exhausted because there is no additional welfare costs connected to collecting tax revenue in this case.

Implementing $\frac{\partial S}{\partial b}=1$ into equation (22) implies that $\bar{\lambda}=1$. Hence, the shadow price of public revenue, $\mu$, equals the average marginal utility of private income, $\bar{\lambda}$. The MCF defined as $\mu / \bar{\lambda}$ consequently equals one.

The first best is attainable because the cost of collecting tax revenue from high income earners is zero. Hence, it is optimal to not distort the labor/ leisure decision of disabled individuals by giving the same transfer to working and non-working disabled. Redistribution to both working and non-working disabled is carried out until the welfare gain of improved redistribution is exhausted, i.e. where the marginal utility of income for disabled equals the marginal utility of income for productive workers.

The welfare gain of spending one unit of public revenue on redistribution equals one in this case. The welfare gain of spending one unit of public revenue on public goods provision has to match this in optimum. Hence, the marginal rate of substitution between private and the public good equals the resource cost of public goods in this case.

\subsection{No extensive margin distortions}

This section calculates MCF when taxation distorts the intensive margin choice of labor supply, but not extensive margin choices. This scenario is implemented into the model framework by assuming that $\frac{\partial h_{1}}{\partial w}$ is positive, and by assuming that the disutility of entering the labor market, $\alpha$, is large. The shadow value of public funds, $\mu$, is given by equation (21). Equation (15) implies that the number of working disabled becomes marginal. Hence, equation (25) implies that

$$
\text { (30) } \frac{\partial S}{\partial b} \approx \mu
$$

Equation (26), (30) and $N=0$ gives 
(31) $M C F=\frac{\mu}{\frac{\hat{N}+\bar{N} \mu}{\hat{N}+\bar{N}}}>1$

Labor force data is presented in table 3.2.1, see appendix E. Scenarios with labor supply elasticity of 0,1 and 0,2 is reported for both countries. The total tax rate on labor income is found by an assessment of the tax system within each country. Table 3.2.1 report estimates of MCF of approximately 1,1 and 1,05 for the US with an intensive margin labor supply elasticity of 0,2 and 0,1, respectively. Estimates for Norway are slightly higher mainly due to a higher tax rate.

The intuition for these results is that the numerator in the definition of MCF, $\mu$, equals the welfare gain of transferring public funds to non- working disabled. This welfare gain equals the marginal utility of income for non-working disabled, $\frac{\partial S}{\partial b}$, as such transfers do not distort the extensive margin labor choice in this special case. This welfare gain exceeds one because it is not optimal to exhaust the welfare gain of redistribution when taxation creates intensive margin distortions. The welfare gain is also larger than the average marginal utility of income, which equals the the denominator in the definition of MCF. The welfare gain is larger because the marginal utility of income for non- working exceeds the marginal utility of income for the remaining population. Hence, the MCF exceeds one in this case to match the higher welfare gain of transfers to non- working.

First order conditions imply that

(32) $(\hat{N}+\bar{N}) \frac{\partial f}{\partial z}=\mu q$

Hence, the marginal welfare gain of public goods provision, the left hand side, equals the shadow value of public funds multiplied by the price of public goods, the right hand side. The shadow value of public funds also equals the welfare cost of colleting additional tax revenue by increasing the income tax rate. This can be illustrated by taking the derivative of the welfare measure with respect to the tax rate, and dividing by the derivative of the tax revenue with respect to the tax rate. Equation (30) shows that the marginal welfare gain of transfers equals the shadow value of public funds. Hence, the welfare cost of collecting tax revenue equals the welfare gain of spending tax revenue. The welfare gain is equalized between different types of spending, i.e. transfers or provision of public goods. 
A higher average marginal utility of income lowers the value of public funds measured in units of private income. The willingness to pay for public goods is however reduced as the marginal utility of income for non- working is increased. These effects are identified by implementing equation (20) into equation (27). This modified Samuelson rule show that the willingness to pay for public goods, the left hand side, is reduced by an increase in the average marginal utility of income (the denominator on the left hand side). The reduction in $\mathrm{MCF}$, on the right hand side of the modified Samuelson rule, is identical. This reduction in MCF explains why MCF is smaller than the welfare gain of transfers, $\frac{\partial S}{\partial b}$, see table 3.2.1.

Table 3.2.1. MCF for Norway and the US with no extensive margin distortions

\begin{tabular}{|l|l|l|l|l|l|l|l|l|l|}
\hline Country & $\hat{N}$ & $\bar{N}$ & $N$ & $E l_{w} h$ & $t$ & $\mu$ & $\frac{\partial S}{\partial b}$ & $\begin{array}{l}\text { MCF }= \\
\text { MCF }\end{array}$ & Samuelson \\
\hline Norway & 2,619 & 1,349 & 0 & 0,1 & 0,5 & 1,111 & 1,111 & 1,07 & 1,073 \\
\hline Norway & 2,619 & 1,349 & 0 & 0,2 & 0,5 & 1,25 & 1,25 & 1,152 & 1,165 \\
\hline USA & 156,76 & 70 & 0 & 0,1 & 0,4 & 1,071 & 1,071 & 1,048 & 1,049 \\
\hline USA & 156,76 & 70 & 0 & 0,2 & 0,4 & 1,154 & 1,154 & 1,102 & 1,106 \\
\hline
\end{tabular}

\subsection{Both intensive and extensive margin distortions}

This section estimates MCF when it is assumed that taxation distort both the intensive and the extensive margin choice of labor supply. Consider the case where $\frac{\partial h_{1}}{\partial w}$ is positive and where $\alpha$ and the initial value of $S(0)$ is chosen to obtain the required stock of disabled that are working, and the relevant extensive margin labor supply elasticity. Equation (21) and (24) implies that $b>a$, i.e. that transfers to non- working disabled is larger than transfers to working disabled. This result and equation (21) and (23) implies that $\frac{\partial S}{\partial b}>1$. Equation (21), (25) and (26) determines the value of MCF. Note that this solution differs from the result in Saez (2002), where income is taxed with negative rates at low income levels.

Data on how many disabled (and others on social welfare) that are working is required to estimate MCF in this case. The value of $\mathrm{N}$ is obtained by assessments of data even though $\mathrm{N}$ is an endogenous variable within the model framework. It is estimated that approximately 30 
percent of individuals with severe disability within EU countries chose to work, see Eurostat (2001). A substantial share of these individuals receives social welfare benefits. It is however difficult to pinpoint the exact number. Two scenarios are analyzed where 10 and 20 percent of individuals classified as disabled choose to work. These individuals are assumed to be included in the labor force when data is presented. Results and adjusted labor force date is presented in table 3.3.1.

Table 3.3.1. MCF for Norway and the US with both intensive and extensive margin distortions

\begin{tabular}{|c|c|c|c|c|c|c|c|c|c|}
\hline Country & $\hat{N}$ & $\bar{N}$ & $N$ & $E l_{w} h$ & $t$ & $\mu$ & $\frac{\partial S}{\partial b}$ & $\begin{array}{l}\mathrm{MCF}= \\
\mu / \bar{\lambda}\end{array}$ & $\begin{array}{l}\text { MCF } \\
\text { Samuelson }\end{array}$ \\
\hline $\begin{array}{l}\text { Norway } \\
20 \%\end{array}$ & 2,282 & 1,686 & 0,337 & 0,1 & 0,5 & 1,111 & 1,143 & 1,059 & 1,064 \\
\hline $\begin{array}{l}\text { Norway } \\
10 \%\end{array}$ & 2,47 & 1,5 & 0,15 & 0,1 & 0,5 & 1,111 & 1,125 & 1,066 & 1,069 \\
\hline $\begin{array}{l}\text { USA } \\
20 \%\end{array}$ & 139,26 & 87,5 & 17,5 & 0,1 & 0,4 & 1,071 & 1,090 & 1,042 & 1,044 \\
\hline $\begin{array}{l}\text { USA } \\
10 \%\end{array}$ & 148,98 & 77,78 & 7,78 & 0,1 & 0,4 & 1,071 & 1,0795 & 1,045 & 1,047 \\
\hline $\begin{array}{l}\text { Norway } \\
20 \%\end{array}$ & 2,282 & 1,686 & 0,337 & 0,2 & 0,5 & 1,25 & 1,333 & 1,123 & 1,144 \\
\hline $\begin{array}{l}\text { Norway } \\
10 \%\end{array}$ & 2,47 & 1,5 & 0,15 & 0,2 & 0,5 & 1,25 & 1,286 & 1,139 & 1,155 \\
\hline $\begin{array}{l}\text { USA } \\
20 \%\end{array}$ & 139,26 & 87,5 & 17,5 & 0,2 & 0,4 & 1,154 & 1,200 & 1,087 & 1,095 \\
\hline $\begin{array}{l}\text { USA } \\
10 \%\end{array}$ & 148,98 & 77,78 & 7,78 & 0,2 & 0,4 & 1,154 & 1,174 & 1,095 & 1,101 \\
\hline
\end{tabular}

Table 3.3.1 report estimates of MCF below 1,1 for the US economy. Estimates for the Norwegian economy are slightly higher. Estimates are lower compared to the case without extensive margin distortions. The explanation is that the possibility to limit transfers to non- 
working disabled with a higher marginal utility of income contributes to increase the welfare gain of transfers within this scenario. Such transfers, however, generates a distortion in the extensive margin choice of labor/ leisure. This distortions is not completely neutralized by transfers to working disabled because collecting tax revenue to finance transfers create distortions in the intensive margin labor/ leisure choice of working individuals. Hence, it is optimal to restrict redistribution to non- working disabled to prevent both intensive and extensive margin distortions. This explains why the marginal utility of income for nonworking, $\frac{\partial S}{\partial b}$, is larger than the shadow value of public funds, $\mu$, see table 3.3.1. The larger marginal utility of income for non- working contributes to increase the average marginal utility of income. A higher average marginal utility of income leads to a proportional reduction in both the willingness to pay for public goods, and the MCF. The explanation for this is presented in the previous section. Table 3.3.1 show that the reduction in MCF is modest compared to the previous section.

The marginal welfare gain of public goods provision is equalized with the shadow value of public funds, $\mu$, multiplied with the price of public goods. A fixed combination of intensive margin labor supply elasticity and income tax rate determines the shadow value of public funds. Hence, the supply of public funds is determined by the tax rate and the intensive margin labor supply elasticity even though the MCF is lower.

\subsection{Transfers to working disabled equals transfers to all workers}

Previous sections assumed perfect tagging, where the government is able to differentiate policy between productive and disabled. Policy should be adjusted when tagging is imperfect, i.e. with mobility between groups, see Parson (1996) and Jacquet (2014). One may for example argue that working disabled demonstrate that they are not disabled. The government is unable to differentiate between transfers to productive and disabled that are working in this case. This scenario is implemented into the model framework by assuming that transfers to working disabled, $a$, is also given to productive workers even though such transfers are not observed in most countries.

Simple calculations show that the only difference in the calculation of MCF is a new equation to determine the marginal utility of income for non-working disabled, $\frac{\partial S}{\partial b}$.

(33) $\frac{\partial S}{\partial b}=\frac{\mu(\bar{N}-N)}{\bar{N}-N+(1-\mu)(N+\hat{N})}$ 
Table 3.4.1 present results for Norway and the US in the case where 20 percent of disabled are assumed to work, and the intensive margin labor supply elasticity equals 0,1 .

Table 3.4.1. MCF for Norway and the US without differentiation of transfers between workers

\begin{tabular}{|l|l|l|l|l|l|l|l|l|l|}
\hline Country & $\hat{N}$ & $\bar{N}$ & $N$ & $E l_{w} h$ & $t$ & $\mu$ & $\frac{\partial S}{\partial b}$ & $\mathrm{MCF}=$ & $\mathrm{MCF}$ \\
\hline $\begin{array}{l}\text { Norway } \\
20 \%\end{array}$ & 2,282 & 1,686 & 0,337 & 0,1 & 0,5 & 1,111 & 1,416 & 0,973 & 1,00 \\
\hline USA & 139,26 & 87,5 & 17,5 & 0,1 & 0,4 & 1,071 & 1,273 & 0,988 & 1,00 \\
\hline
\end{tabular}

Table 3.4.1 report estimates of MCF slightly below 1 for both the Norwegian and the US economy in this case. The explanation is that transfers to non- working disabled generate a welfare gain due to their higher marginal utility of income. The extensive margin choice of labor supply is however distorted. Transfers to working disabled to correct for the distortion is also given to productive workers in this scenario. Collecting tax revenue to finance such transfers generates a welfare loss due to intensive margin distortions. Hence, the welfare cost of correcting for the extensive margin distortion is larger when transfers to working disabled is also given to productive workers. This explains why transfers to non- workers are lower, and their marginal utility of income higher. The larger marginal utility of income for nonworking, see table 3.4.1, generates a larger average marginal utility of income. This increase explains why MCF estimates are substantially reduced in this scenario.

Giving transfers to all workers require a substantial amount of tax revenue. A subsequent increase in the tax rate would have contributed to increase the shadow value of public funds, and this would have increased the MCF estimate. The MCF estimate is however obtained by calibrating the model to present data, including the tax rate. Hence, a potential tax rate increase is excluded by the approach in this study to focus on empirical relevance. Another approach is required to estimate the change in MCF due to policy changes. Note, however, that MCF estimates for both the US and Norway are slightly below one even though the Norwegian income tax rate is 10 percentage points above the US tax rate.

The cost of correcting for extensive margin distortions is reduced when transfers are given to fewer workers because less distorting taxes is needed to finance such transfers. Saez (2002) show that transfers to non-workers in the presence of extensive margin distortions should be 
phased out at middle income levels. Hence, this section is likely to exaggerate the cost of correcting for extensive margin distortions. A higher MCF estimate is likely to emerge when the cost of correcting for extensive margin distortion is reduced.

\section{Conclusion}

Recent literature on the marginal cost of public funds that take account of concerns for the distribution of income estimate MCF around one, see Kaplow (1996), Sandmo (1998), Christiansen (2007) and Jacobs (2013). Estimates differ with assumptions, but the main argument is that the efficiency cost of taxation counter the welfare gain connected to redistribution of income. Hence, there should be no additional cost attached to collecting public funds when public goods are provided. Kleven and Kreiner (2006), on the other hand, argue that the cost of public goods provision may double in countries with a large welfare state due to distortions in the extensive margin choice of labor supply.

The literature has however not investigated how MCF should be adapted in the presence of categorical transfers designed to cope with extensive margin distortions. This study explores how MCF should be adjusted in the presence of extensive margin distortions when categorical transfers redistribute income so that the welfare is maximized. A simple argument uncover that the MCF equals one in the presence of quasilinear utility functions and group specific transfers which eliminate inequality in the average social marginal value of income between groups. The average social marginal value of income is however larger for the disabled group when the size of this group is sufficiently large and lump-sum transfers are constrained to be non-negative, see Slack (2015). The present study investigates implications for MCF in this case, and shows that MCF exceeds one in the presence of categorical transfer systems. The impacts of incorporating extensive margin distortions are marginal and negative compared with a solution where the extensive margin distortion is excluded. The welfare cost of correcting for the extensive margin distortions is larger in a scenario where the government is unable to differentiate between transfers to productive and disabled that are working. MCF estimates are reduced to approximately one for both the US and the Norwegian economy in this case. Hence, MCF should be chosen according to the income transfer system adopted by the government. Estimates for both the US and the Norwegian economy however show that MCF should be set below 1,15. A drastic reduction compared to the recommendation by Kleven and Kreiner (2006). 


\section{References}

Atkinson, A. B. and Stern, N. H., 1974, Pigou, taxation and public goods. Review of Economic Studies, 41, 119128.

Akerlof, G. A., The economics of "tagging" as applied to the optimal income tax, welfare programs, and manpower planning, The American Economic Review, 68. No1, 8-19.

Blundell, R. W., and MaCurdy, T., 1999. Labor supply: a review of alternative approaches, In Ashenfelter, O., Card, D. (Eds.), Handbook of Labor Economics, vol. 3A North-Holland, Amsterdam.

Browning, E. K., 1976, The marginal cost of public funds, Journal of Political Economy, 84, 283-298.

Cogan, J. F., 1981, Fixed costs and labor supply, Econometrica 49, 945-963.

Christiansen, V., 1981._Evaluation of Public Projects under Optimal Taxation._ Review of Economic Studies 48 (3):447_457

Christiansen, V., 2007, Two approaches to determine public good provision under distortionary taxation, National Tax Journal 60(1), 25-43.

Currie, J., 2006, The take-up of social benefits, in poverty, the distribution of income, and public policy, in: David c, John Q, Alan Auerbach. Russel Sage, New York, pp 80-149.

Deaton, A., 2008, Income, Health, and Well-Being around the World: Evidence from the Gallup World Poll, Journal of Economic Perspectives, 22(2), 53-72.

Eissa, N., Liebman, J., 1996, Labor supply responses to the earned income tax credit, Quarterly Journal of Economics, 61, 605-637.

Eissa, N, Kleve, H. J., Kreiner, C. T, 2004, Evaluation of four tax reforms in the United States; Labor supply and welfare effects of single mothers, NBER Working paper no w 10935.

Eurostat, 2001, Disability and social participation in Europe, Office for official publications of the European Communities, Luxembourg.

Heckman, J. J., 1993, What has been learned about labor supply in the past twenty years?, Papers and Proceedings- American Economic Review, 83, 116-121.

Immervoll, H., Kleven, H. J., Kreiner, C. T. and Saez E., 2007, Welfare reform in European Countries: a microsimulation analysis, The Economic Journal, 117, 1-44.

Jacobs, B., 2013, "Marginal Cost of Public Funds is One at the Optimal Tax System", revision, mimeo: Erasmus University Rotterdam.

Jacquet, L., 2014, Tagging and redistributive taxation with imperfect disability monitoring, Soc Choice. Welf, $42 ; 403-435$.

Kaplow, L., 1996, The Optimal Supply of Public Goods and the Distortionary

Cost of Taxation, National Tax Journal 49, 513.533.

Kleven, HJ \& Kreiner, CT 2006, 'The marginal cost of public funds: hours of work versus labor force participation' Journal of Public Economics, vol 90, no. 10-11, pp. 1955-1973.

Meyer, J., Rosenbaum, D., 2001, Welfare, the earned income tax credit, and the labor supply of single mothers, Quarterly Journal of Economics, 66, 1063-1114.

Moffitt, R., 2003, Means-tested transfer programs in the United States, University of Chicago Press, Chicago. 
Kostøl, A. and Mongstad, M., 2014, How Financial Incentives Induce Disability Insurance Recipients to Return to Work, American Economic Review, 104(2), 624-55.

OECD, 2009, Sickness. Disability and work, keeping on track in the economic downturn OECD report and background paper of the high level forum in Stockholm.

Parson, D. O., 1996, Imperfect "tagging" in social insurance programs, Journal of Public Economics, 62, 183207.

Saez, E., 2002, Optimal income transfer programs: intensive versus extensive labor supply responses, The Quarterly Journal of Economics, vol. 117(3) (May), pp. 1039-73.

Sandmo, A., 1998, Redistribution and the marginal cost of public funds, Journal of public economics 70, 365382.

Slack, S. E., 2015, Revisiting the optimal linear income tax with categorical transfers, Economics Letters, 134, 73-77.

Stevenson, B. and Wolfers, J, 2008, Economic Growth and Subjective Well-Being: Reassessing the

Easterlin Paradox, Brookings Papers on Economic Activity, Spring 2008, 1-87.

Stiglitz, J.E. and Dasgupta, P., 1971, Differential taxation, public goods and economic efficiency, Review of Economic Studies, 38, 151-174.

Viard, A. D., 2001, Optimal Categorical Transfer Payments: The Welfare Economics of Limited Lump-Sum Redistribution, Journal of Public Economic Theory, 3 (4), pp. 583-500.

\section{Appendix}

A. The second order condition:

The Lagrangian is additively separable in $z, t$, and the par of transfers $a$ and $b$. Hence, the Lagrangian is concave if each of these separable functions is concave.

The $z$-function:

$$
\text { (A 1) } \frac{\partial^{2} L}{\partial z \partial z}=(\hat{N}+\bar{N}) \frac{\partial^{2} f}{\partial z \partial z}<0
$$

Hence, the $z$ function is strictly concave. 
The $t$-function:

(A 2) $\frac{\partial^{2} L}{\partial t \partial t}=2 \hat{N} w_{1} \frac{\partial l_{1}}{\partial t}(1-\mu)-\mu \hat{N} w_{1} t \frac{\partial^{2} l_{1}}{\partial t \partial t} \leq 0$

The $a$ and $b$-function:

(A 3) $\frac{\partial^{2} L}{\partial a \partial a}=(1-\mu) \frac{1}{\alpha}-\mu \frac{1}{\alpha}<0$

(A 4) $\frac{\partial^{2} L}{\partial b \partial b}=\frac{\partial^{2} S}{\partial b \partial b}\left[\bar{N}-N-\mu \frac{(b-a)}{\alpha}\right]+\left[2(-\mu)+\frac{\partial S}{\partial b}\right] \frac{1}{\alpha} \frac{\partial S}{\partial b} \leq 0$

(A 5) $\frac{\partial^{2} L}{\partial a \partial a} x \frac{\partial^{2} L}{\partial b \partial b}-\left(\frac{\partial^{2} L}{\partial b \partial a}\right)^{2}>0$ is satisfied when

$\left[(1-\mu) \frac{1}{\alpha}-\mu \frac{1}{\alpha}\right] x\left[\frac{\partial^{2} S}{\partial b \partial b}\left[\bar{N}-N-\mu \frac{(b-a)}{\alpha}\right]+\left[2(-\mu)+\frac{\partial S}{\partial b}\right] \frac{1}{\alpha} \frac{\partial S}{\partial b}\right]-\left[-(1-\mu) \frac{1}{\alpha} \frac{\partial S}{\partial b}+\mu \frac{1}{\alpha}\right]^{2}>0$

The solutions are limited to cases which satisfy these conditions.

B. The first order conditions:

The Envelope Theorem is employed to calculate the impact of a marginal change in the tax rate. The equilibrium condition which determines the number of disabled that are working is employed to calculate the impact of a marginal change in transfers.

(B 1) $\frac{\partial L}{\partial z}=(\hat{N}+\bar{N}) \frac{\partial f}{\partial z}-\mu q=0$

(B 2) $\frac{\partial L}{\partial t}=\hat{N}\left[-w_{1}\left(T-l_{1}(t)\right)\right]+\mu\left[\hat{N} w_{1}\left(T-l_{1}(t)\right)-\frac{\partial l_{1}}{\partial t} \hat{N} t w_{1}\right]=0$ 
(B 3) $\frac{\partial L}{\partial b}=\frac{\partial S}{\partial b}(\bar{N}-N(b, a))-\mu\left[\bar{N}-N(b, a)-\frac{\partial N}{\partial b} b+\frac{\partial N}{\partial b} a\right]=0$

(B 4) $\frac{\partial L}{\partial a}=N(b, a)+\mu\left[-N(b, a)+\frac{\partial N}{\partial a}(b-a)\right]=0$

The budget constraint implies that

(B 5) $\hat{N} t w_{1}\left(T-l_{1}(t)\right)=q z+(\bar{N}-N(b, a)) b+N(b, a) a$

Hence, equation (B 1) gives

$$
\text { (B 6) }(\hat{N}+\bar{N}) \frac{\partial f}{\partial z}=\mu q
$$

Equation (B 2) and (5) gives

$$
\text { (B 7) } \mu\left[1-\frac{\frac{\partial l_{1}}{\partial t} t w_{1}}{w_{1}\left(T-l_{1}(t)\right)}\right]=1
$$

Equation (B 3) and (15) gives

$$
\text { (B 8) } \frac{\partial S}{\partial b}=\mu\left[1-\frac{\frac{\partial N}{\partial b}(b-a)}{\bar{N}-N(b, a)}\right]
$$

Equation (B 4) and (15) gives

(B 9) $\frac{\partial L}{\partial a}=(1-\mu) N(b, a)+\mu \frac{\partial N}{\partial a}(b-a)=0$

The MCF is defined as the shadow value of public funds divided by the average marginal utility of income, $\bar{\lambda}$.

(B 10) $M C F=\frac{\mu}{\bar{\lambda}}$ 


$$
\text { (B 11) } \frac{(\hat{N}+\bar{N}) \frac{\partial f}{\partial z}}{\bar{\lambda}}=M C F q
$$

Equation (B 7) gives

(B 12) $\mu=\frac{1}{\left[1-\frac{\frac{\partial l_{1}}{\partial t} t w_{1}}{w_{1}\left(T-l_{1}(t)\right)}\right]}>1$ if $\frac{\partial l_{1}}{\partial t}>0$ and $t>0$.

The empirical implementation, however, require some additional calculations. First, the definition of leisure,

(B 13) $l_{1}=T-h_{1}$,

imply that

(B 14) $\frac{\partial l_{1}}{\partial t}=-\frac{\partial h_{1}}{\partial t}$

Second, the definition of the after tax wage rate,

(B 15) $w=(1-t) w_{1}$

imply that

(B 16) $\frac{\partial w}{\partial t}=-w_{1}$

Equation (B 13)-(B 16), together with the definition

$$
\text { (B 17) }-\frac{\partial h_{1}}{\partial t}=-\frac{\partial h_{1}}{\partial w} \frac{\partial w}{\partial t}
$$

Imply that

(B 18) $\frac{\partial l_{1}}{\partial t}=w_{1} \frac{\partial h_{1}}{\partial w}$

Inserting this into equation (B 12) gives

(B 19) $\mu=\frac{1}{\left[1-\frac{\partial h_{1}}{\partial w} \frac{w}{h_{1}} \frac{t}{(1-t)}\right]}$ 
The average marginal utility of income is defined as

(B 20) $\bar{\lambda}=\frac{\hat{N}+N+(\bar{N}-N) \frac{\partial S}{\partial b}}{\hat{N}+\bar{N}}$

The marginal utility of income for non-working disabled, $\frac{\partial S}{\partial b}$, is required to calculate the average marginal utility of income. Implementing equation (B 12) into (B 8) gives

$$
\text { (B 21) } \frac{\partial S}{\partial b}=\frac{\left[1-\frac{\frac{\partial N}{\partial b}(b-a)}{\bar{N}-N(b, a)}\right]}{\left[1-\frac{\frac{\partial l_{1}}{\partial t} t w_{1}}{w_{1}\left(T-l_{1}(t)\right)}\right]}>1 \text { if } \frac{\partial l_{1}}{\partial t}>0, \frac{\partial N}{\partial b}<0 \text { and } b>a \text {. }
$$

Equation (B 9) implies that

(B 22) $\frac{\partial N}{\partial a}(b-a)=\frac{(1-\mu)}{(-\mu)} N$

Equation (15) implies that

(B 23) $\frac{\partial N}{\partial a}=\frac{1}{\alpha}$ and $\frac{\partial N}{\partial b}=-\frac{1}{\alpha} \frac{\partial S}{\partial b}$

Equations (B 22) and (B 23) implies that

(B 24) $\frac{\partial N}{\partial b}(b-a)=-\frac{(1-\mu)}{(-\mu)} N \frac{\partial S}{\partial b}$

Equation (B 24) into equation (B 8) gives 
(B 25) $\frac{\partial S}{\partial b}=\frac{\mu(\bar{N}-N)}{\bar{N}-N+(1-\mu) N}$

Equation (B 20) and (B 10) implies that

(B 26) $M C F=\frac{\mu}{\frac{\hat{N}+N+(\bar{N}-N) \frac{\partial S}{\partial b}}{\hat{N}+\bar{N}}}$

Equation (B 25) and (B 19) together with equation (B 26) determines MCF as a function of labor force data, the intensive margin labor supply elasticity, and the income tax rate.

C. The marginal rate of substitution

The point of departure is the individualistic social welfare function. A marginal unit of private consumption, $c_{m \text { arg }}$, is included for each consumer. The welfare function is differentiated w.r.t. per person consumption, $c_{m \text { arg }}$, and the public good. This gives

$$
\text { (C 1) } \frac{(\hat{N}+\bar{N}) \frac{\partial f}{\partial z}}{\hat{N}+N+(\bar{N}-N) \frac{\partial S}{\partial b}}
$$

The welfare maximizing governments' marginal rate of substitution between private and public goods is obtained by multiplying equation (C 1) with the number of individuals, $(\hat{N}+\bar{N})$.

D. MCF based on deviations from the Samuelson rule

The point of departure is the first order equation (B 6)

$$
\text { (D 1) }(\hat{N}+\bar{N}) \frac{\partial f}{\partial z}=\mu q
$$

Hence,

$$
\text { (D 2) }(\hat{N}+N) \frac{\partial f}{\partial z}+(\bar{N}-N) \frac{\partial f}{\partial z}=\mu q
$$

Hence, 


$$
\text { (D 3) }(\hat{N}+N) \frac{\partial f}{\partial z}+(\bar{N}-N) \frac{\frac{\partial f}{\partial z}}{\frac{\partial S}{\partial b}}+(\bar{N}-N) \frac{\frac{\partial f}{\partial z}}{\frac{\partial S}{\partial b}}\left(\frac{\partial S}{\partial b}-1\right)=\mu q
$$

Hence,

$$
\text { (D 4) }(\hat{N}+N) \frac{\partial f}{\partial z}+(\bar{N}-N) \frac{\frac{\partial f}{\partial z}}{\frac{\partial S}{\partial b}}=\mu q-(\bar{N}-N) \frac{\frac{\partial f}{\partial z}}{\frac{\partial S}{\partial b}}\left(\frac{\partial S}{\partial b}-1\right)
$$

Substituting $\frac{\partial f}{\partial z}$ on the right hand side with equation (D 1) gives

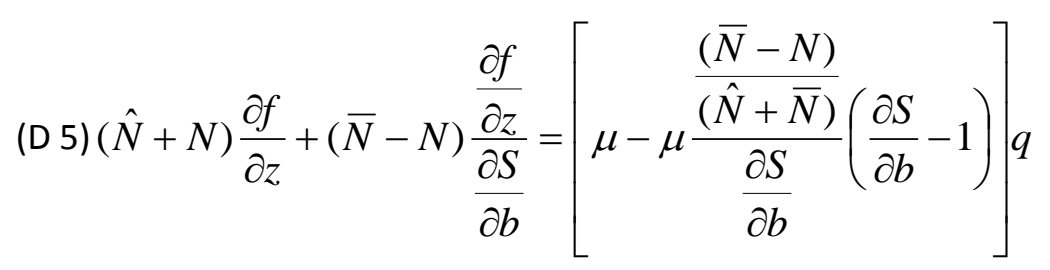

Hence, $M C F_{\text {Samuelson }}$ is given by the expression

$$
\text { (D 6) } M C F_{\text {Samuelson }}=\mu-\mu \frac{\frac{(\bar{N}-N)}{(\hat{N}+\bar{N})}}{\frac{\partial S}{\partial b}}\left(\frac{\partial S}{\partial b}-1\right)
$$

E. Labor force data

The case of US is illustrated by implementing data for 2013. The number on social disability transfers (app. 9 mill according to Social security administration), unemployment (8 million in 2015 according to the US Department of labor), on Medicare (50 million according to the Kaiser Family foundation), and public pensions (Estimate of 3 million). The total number on social benefit transfers, $\bar{N}$, amounts to 70 million. The number of employed amounts to 156,76 million individuals according to OECD. Sensitivity tests are conducted which excludes people on Medicare from the group on social benefit transfers. The impact on MCF estimates are modest. 
The case of Norway is illustrated by implementing data for 2013. The number on social disability transfers, unemployment benefit, sickness transfers and public pensions, $\bar{N}$, amounts to 1349 thousand. The total number of working individuals, $\hat{N}$, amounts to 2619 thousand. One may however argue that individuals on public pension should be excluded from the disabled group as many have accumulated wealth that can be consumed. This wealth effect as well as their desire to consume may depress their marginal utility of income.

The income tax wedge on average income earners amounts to 31,5 percent in the US, and 37 percent in Norway in 2014 according to OECD. The sales tax range from 0 to almost 10 percent in the US. VAT on most consumer goods in Norway equals 25 percent. There is also substantial taxation of corporate income in both countries, as well as real estate taxation in the US. Immervoll et al. (2007) report total marginal tax rates above 60 percent for other Nordic countries. Total tax revenue as a share of GDP only amounts to 25,4 percent of GDP in the US and 40,8 percent in Norway in 2013 according to OECD. The average tax rate on labor earnings is of course larger as the tax on capital earnings is lower.

The effective tax rate on labor earnings is also influenced by public spending, tax deductions and tax evasion. Tax payments to finance public pensions in Norway resemble mandatory savings schemes, as income tax payments are linked with pension transfers. Hence, one may argue that such taxes should be exempted from the effective marginal tax rate. One may also argue that certain types of public spending function as subsidies on private consumption. Public roads may for example function as a subsidy on the purchase of cars. Public education stimulates investment in human capital, and hence, earnings. It is however difficult to determine the exact impact on the effective marginal tax rate. An overall assessment suggest that the total effective tax rate on labor earnings amounts to approximately 40 percent in the US, and 50 percent in Norway. 